Miriam Soares Leite

Contribuições de Basil Bernstein e Yves Chevallard para a discussão do conhecimento escolar

Dissertação de Mestrado

Dissertação apresentada ao Programa de Pós-Graduação em Educação da PUC-Rio como requisito parcial para obtenção do grau de Mestre em

Educação.

Orientadora: Vera Maria Ferrão Candau

Rio de Janeiro

Fevereiro de 2004 


\section{“CONTRIBUIÇÕES DE BASIL BERNSTEIN E YVES CHEVALLARD \\ PARA A DISCUSSÃO DO CONHECIMENTO ESCOLAR"}

Dissertação apresentada como requisito parcial para obtenção do grau de Mestre em Educação do Departamento de Educação do Centro de Teologia e Ciências Humanas da PUC-Rio. Aprovada pela Comissão Examinadora abaixo assinada.

Prof $^{a}$ VERA CANDAU

Orientadora

PUC-Rio

Profa ALICIA BONAMINO

Presidente

PUC-Rio

Prof $^{\mathrm{a}}$ CARMEN TERESA GABRIEL ANHORN

Estácio de Sá

Prof. JURGEN HEYE

Coordenador Setorial do Centro

de Teologia e Ciências Humanas - PUC-Rio

Rio de Janeiro, 16/02/2004 
Todos os direitos reservados. É proibida a reprodução total ou parcial deste trabalho sem autorização do autor, orientador e da universidade.

Miriam Soares Leite Licenciada em História pela Universidade Federal Fluminense, em 1992, atua em ensino e pesquisa no campo da Didática Geral e da Metodologia do Ensino de História.

Ficha Catalográfica

\begin{tabular}{|c|}
\hline Leite, Miriam Soares \\
\hline $\begin{array}{l}\text { Contribuições de Basil Bernstein e Yves } \\
\text { Chevallard para a discussão do conhecimento } \\
\text { escolar / Miriam Soares Leite ; orientadora: Vera } \\
\text { Maria Ferrão Candau. - Rio de Janeiro : PUC, } \\
\text { Departamento de Educação, } 2004 \text {. }\end{array}$ \\
\hline 131 f. ; $30 \mathrm{~cm}$ \\
\hline 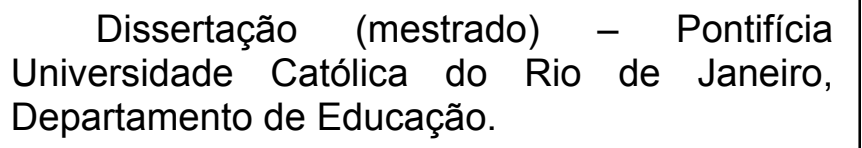 \\
\hline Inclui referências bibliográficas. \\
\hline $\begin{array}{l}\text { 1. Educação - Teses. 2. Transposição } \\
\text { didática. 3. Recontextualização. 4. Discurso } \\
\text { pedagógico. 5. Epistemologia escolar. } 6 . \\
\text { Conhecimento escolar. 7. Saber escolar. I. } \\
\text { Candau, Vera Maria Ferrão. II. Pontifícia } \\
\text { Universidade Católica do Rio de Janeiro. } \\
\text { Departamento de Educação. III. Título. }\end{array}$ \\
\hline
\end{tabular}

CDD: 370 


\section{Agradecimentos}

À minha orientadora, professora Vera Maria Ferrão Candau, pela confiança e apoio constantes e pelo exemplo que tem representado para mim.

Aos professores do Programa de Pós-Graduação em Educação da PUC-Rio, pela generosidade da acolhida e pelas muitas contribuições que se fazem presentes neste trabalho.

Às amigas do Gecec - Grupo de Estudos sobre Cotidiano, Educação e Cultura(s) - pela amizade e solidariedade que têm marcado nosso convívio.

À Faperj e à PUC-Rio, pelos auxílios financeiros concedidos, que viabilizaram a realização desta pesquisa.

Aos colegas da PUC, pelo companheirismo, estímulo e afeto recebidos.

Aos professores que participaram da banca examinadora.

A todos os amigos e familiares, pelos diversos e fundamentais momentos de incentivo e colaboração.

A todos os meus ex-alunos, pelo desafio e encanto que representaram nos anos de magistério que antecederam o Curso de Mestrado, dando sentido a este estudo e à sua continuidade. 


\section{Resumo}

LEITE, Miriam Soares; CANDAU, Vera Maria Ferrão. Contribuições de Basil Bernstein e Yves Chevallard para a discussão do conhecimento escolar. Rio de Janeiro, 2004. 116 p. Dissertação de Mestrado. Departamento de Educação, Pontifícia Universidade Católica do Rio de Janeiro.

Este estudo visa contribuir para as reflexões sobre a constituição do conhecimento escolar, com base em uma pesquisa bibliográfica que buscou identificar e discutir a aplicação dos conceitos de transposição didática, de Yves Chevallard, e de recontextualização discursiva, de Basil Bernstein. Pretendeu proporcionar, desta forma, uma visão geral das diversas leituras possíveis das proposições desses autores, no recorte acima definido. Para tanto, foram analisadas as publicações de Bernstein e Chevallard que se relacionam mais diretamente com a temática em discussão nesta pesquisa, teses brasileiras recentes que operaram com esses conceitos, além dos trabalhos apresentados a partir de 1998 nas reuniões anuais da Associação Nacional de Pós-Graduação e Pesquisa em Educação (Anped), nos Encontros Nacionais de Didática e Prática de Ensino (Endipe), e nas três revistas categorizadas pelo sistema Qualis como de "nível internacional A" - Cadernos de Pesquisa, Educação e Sociedade e Revista Brasileira de Educação. No decorrer deste processo de pesquisa e reflexão, colocaram-se ainda, como questões paralelas, a discussão das fronteiras dos campos disciplinares do Currículo e da Didática, e a problemática da interpretação de textos teóricos. Conclui-se o estudo, apontando potencialidades e especificidades dos conceitos de transposição didática e de recontextualização discursiva, bem como a importância da incorporação da discussão de tais conceitos na formação de professores.

\section{Palavras-chave}

Transposição didática, recontextualização, discurso pedagógico, epistemologia escolar, conhecimento escolar, saber escolar. 


\section{Abstract}

LEITE, Miriam Soares; CANDAU, Vera Maria Ferrão. Contributions to the discussion of school knowledge provided by Basil Bernstein and Yves Chevallard. Rio de Janeiro, 2004. 116 p. Dissertation. Departamento de Educação, Pontifícia Universidade Católica do Rio de Janeiro.

The objective of this study is to contribute towards reflections regarding school knowledge constitution based upon bibliographical research, aimed at the identification and application of the following concepts: instructional transposition developed by Yves Chevallard and discourse recontextualization by Basil Bernstein. With the intent to provide an overview of several possible interpretations of these authors' theoretical proposals within the above-mentioned approach, an analysis was conducted of the following: publications by Bernstein and Chevallard directly related to the subject discussed in this research, recent Brazilian thesis that applied these concepts and, starting in 1998, articles presented during annual meetings of the Associação Nacional de Pós-Graduação e Pesquisa em Educação (Anped), and during the Encontros Nacionais de Didática e Prática de Ensino (Endipe), as well as published in the three magazines categorized by the Qualis system as "international A level" (Cadernos de Pesquisa, Educação e Sociedade and Revista Brasileira de Educação). In the course of this reflection and research process, parallel issues were raised, such as the Curriculum and Instruction disciplinary fields boundaries and the interpretation of theoretical writings. In the conclusion of this dissertation, potentialities and specific features of instructional transposition and discourse recontextualization were underscored, as well as the importance of incorporating the discussion of these concepts to the teachers' education curriculum.

\section{Keywords}

Instructional transposition, recontextualization, pedagogic discourse, school epistemology, school knowledge. 


\section{Sumário}

1. Introdução --o-- 9

2. Basil Bernstein e o conceito de recontextualização discursiva -- 20

2.1. Bernstein e a Nova Sociologia da Educação --------------- 20

2.2. Origens, influências, enquadramentos ------------------- 23

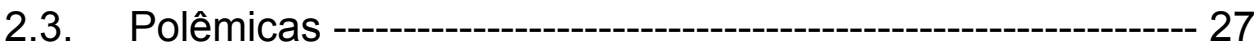

2.4. Por uma teoria sociológica da pedagogização da

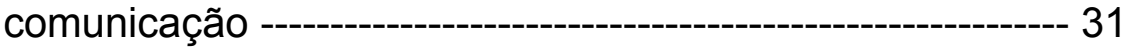

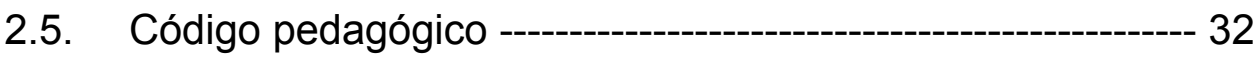

2.6. Recontextualização e pedagogização do conhecimento -- 37

3. Yves Chevallard e o conceito de transposição didática 45

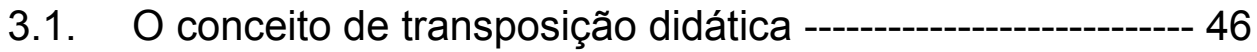

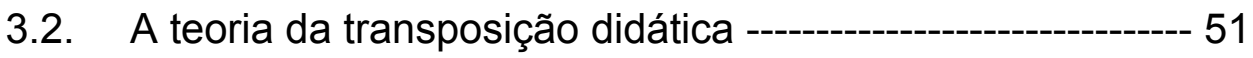

3.3. Polêmicas -----o- 62

3.3.1. O professor e a teoria da transposição didática --------- 62

3.3.2. O embate com outras didáticas --- 64

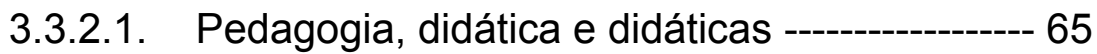

3.3.2.2. A questão do "saber sábio" ---------------------- 68

3.3.2.3. A escola transpõe ou cria seus próprios saberes? ----o- 71

4. A discussão da constituição do conhecimento escolar na

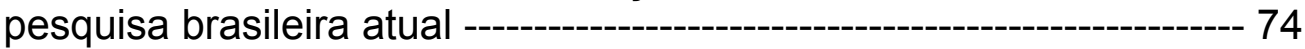

4.1. Anped --- 76

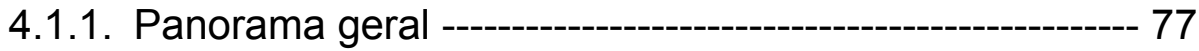

4.1.2. Diferentes enfoques -- 82

4.1.2.1. Processos de didatização dos saberes -------- 83 
4.1.2.2. História dos currículos-------------------------- 85

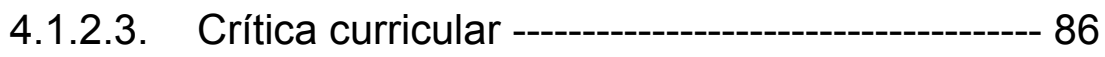

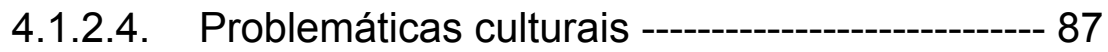

4.1.2.5. Currículo oficial e resistência -------------------- 89

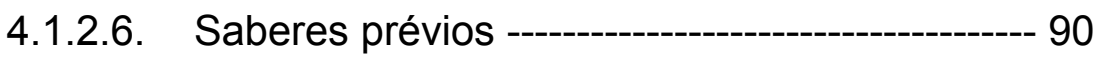

4.1.2.7. Epistemologia do conhecimento escolar ------- 91

4.2. Endipe ------------ 92

4.2.1. Panorama geral --------------- 93

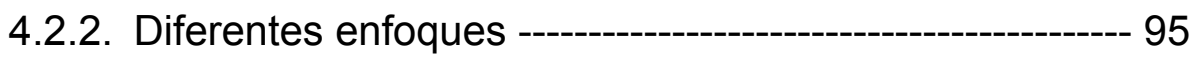

4.3. Periódicos -- 97

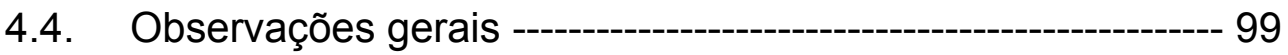

5. Considerações finais: potencialidades e especificidades dos conceitos de recontextualização e de transposição didática ----------102

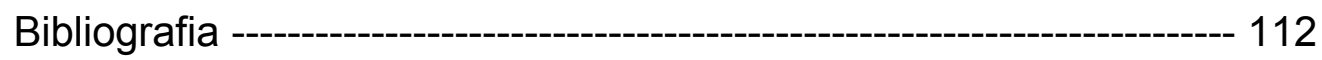

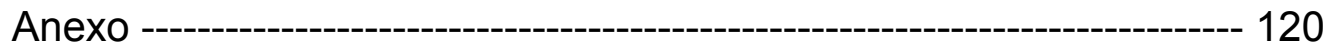

